\title{
A TECNOLOGIA REVOLUCIONANDO O PROCESSO DE ENSINO APRENDIZAGEM? A EXPERIÊNCIA DE PARAGUAÇU NO ESTADO DE MINAS GERAIS
}

\author{
Dimas dos Reis RIBEIRO ${ }^{1}$ \\ Renata Aparecida Martins GONÇALVES ${ }^{2}$ \\ Thais Alessandra MOREIRA ${ }^{3}$ \\ Tatiana BELTRÃO ${ }^{4}$
}

RESUMO: Não temos como negar que os avanços tecnológicos estão a cada dia mais perto das pessoas e aos poucos tem tomado os ambientes escolares com uma formulação discursiva de que promoverá uma maior integração dos educandos e aperfeiçoando o método de ensino aprendizagem, como sinaliza estar ocorrendo no Centro de Educação Fazendo Acontecer "Ana Paula Silva Gomes", escola privada do município mineiro de Paraguaçu. Será que é isso mesmo que tem ocorrido? Sabemos que a utilização incorreta dessa ferramenta pode bloquear o desenvolvimento da criatividade e a capacidade de sintetizar as informações recebidas. Na maioria das vezes por falta de discernimento, as próprias crianças e jovens serão os mais prejudicados por essa sedutora tecnologia, visto que os pais, em função da própria lógica do mundo do trabalho não desfrutam de condições para supervisionar os estudos que se realizam diante dos computadores e da internet. Além do mais, na própria sala de aula pode ocorrer um distanciamento e frieza na relação entre educandos e educadores. De tal forma que os pais, educadores e profissionais da educação precisam acompanhar com muita cautela a implantação dessas tecnologias inovadoras em salas de aula para que não seja comprometido todo o processo de ensino aprendizagem e tenhamos no futuro um exército de pessoas que não saberão escrever, ler e contar.

PALAVRAS-CHAVE: Educação. Tecnologia. Inovação. Desafios. Contradições.

\section{Introdução}

Atualmente muito se tem afirmado que as novas tecnologias trazem uma grande vantagem à educação, que é o envolvimento dos educandos com mais facilidades atividades e tarefas escolares.

\footnotetext{
${ }^{1}$ Docente. UFMA - Universidade Federal do Maranhão - Campus Pinheiro. Departamento de Ciências Humanas. São Luís - MA - Brasil.65080-805 - profdimas@uol.com.br.

${ }^{2}$ Discente do Curso de Pedagogia. UNIFENAS - Universidade José do Rosário Vellano. Alfenas - MG Brasil. 37130-000 - renataserrania@ hotmail.com.

${ }^{3}$ Discente do Curso de Pedagogia. UNIFENAS - Universidade José do Rosário Vellano. Alfenas - MG Brasil. 37130-000 - thaizinhaalessandra@ hotmail.com.

${ }^{4}$ Discente do Curso de Pedagogia. UNIFENAS - Universidade José do Rosário Vellano. Alfenas - MG Brasil.37130-000 - tatipcu@ hotmail.com.
} 
Ela ajuda também em outras habilidades como, ortografia, atenção, coordenação motora, percepção, aquisição de novos saberes, compartilhamento de ideias, interação social, entre outros.

No entanto se não for utilizada com cuidado acaba por alienar quem a usa, voltando-se como um meio de deseducação social. As ações cotidianas passam a serem vistas como enfadonhas e desnecessárias. Acabamos por perder a naturalidade do "bom dia" e até mesmo do "oi". As brincadeiras infantis (em sua maioria) agora estão contidas em algum software e os jogos são realizados (sim, algumas vezes em grupos, pela rede tecnológica) pelos computadores e celulares, nas suas mais variadas formas (EDUCANDO.COM, 2014).

Assim, nós educadores estamos tendo nossa criatividade desafiada para utilizarmos a nosso favor essas ferramentas inovadoras que estiveram presentes no nosso processo de formação profissional e que agora nos convida para alçar novos voos, nos adequando a esse momento singular em que o nosso profissionalismo, a nossa capacidade de mudar e inovador está sendo colocada à prova.

As Tecnologias da Informação e da Comunicação têm vindo a
provocar uma enorme mudança na Educação, originando novos
modos de difusão do conhecimento, de aprendizagem, e,
particularmente, novas relações entre professores e alunos. As pesadas
enciclopédias foram substituídas pelas enciclopédias digitais, pela
consulta de portais académicos e outros locais diversificados.
Passamos a utilizar sistemas electrónicos e apresentações coloridas
para tornar as aulas mais atractivas e, frequentemente, deixamos de
lado o tradicional quadro negro e o giz e passamos directamente para
as superfícies e projecções interactivas (BACELAR, 2010).

Educação tecnologicamente contemporânea não significa apenas escolas com computadores, crianças e jovens navegando na internet, comunidades virtuais de aprendizagem e coisas semelhantes. Tudo isto é importante, sem dúvida. Mas uma escola que não relaciona a tecnologia com a vida não cumpre o seu papel.

Devemos permanentemente avançar e inovar na forma de ensinar. É preciso acompanhar o tempo presente, suas tecnologias e seus desafios. Crianças que vão para a escola com prazer, com certeza aprendem muito mais.

Quando a tecnologia chega à sala de aula, logo o interesse é despertado nos alunos, todos querem aprender a mexer, a usar e enfim usar e ser um ativo de tal meio.

Atualmente, o meio em que vivemos está permeado pelo uso de técnicas e recursos tecnológicos, fazendo do computador uma ferramenta que vem auxiliar o processo ensino/aprendizagem nas questões do cotidiano trazidas até a sala de aula. É muito importante o 
compromisso do docente e a escola deve estar atualizada e disposta a questionar e discutir os aspectos da informática dentro da evolução da sociedade incluindo nesse processo as transformações às vezes não percebíveis

Os meios de comunicação são verdadeiras "extensões do homem", devemos usá-los desde a infância num sentido construtivo. Desde o pré-escolar até o $2^{\circ}$ grau, a matéria da comunicação e expressão deveria receber uma ênfase maior, promovendo o crescimento integral das pessoas de todas as classes sociais adotando para tanto varias formas de comunicação, tais como as alternativas, participatória, militante, popular, de resistência e por que não a folclórica ou tradicional.

Através das relações diárias, o ser universal (o homem) pensa, sente e age a todo instante através das relações sociais de que fazem parte. É preciso haver uma educação voltada para a cidadania. As pessoas agem a partir de uma relação de trocas culturais, modificam a si mesmas, aos outros e à natureza (DALAPOSSA, 2014).

E agindo assim devemos fazer no processo de ensino aprendizagem uma interação permanente e despertar para uma práxis liberadora, usando a favor do processo de ensino aprendizagem todas as ferramentas disponíveis, mas sem perder a perspectiva humana e a emancipação de nosso educandos.

Só educadores críticos e dialéticos saberão selecionar as fontes e sua veracidade, os instrumentos e sua possibilidades de uso, bem como as informações mais precisas e adequadas ao processo educativo.

Assim, através de uma combinação reflexiva que seja capaz de combinar as perspectivas teóricas e práticas nos possibilitará a percepção da diversidade de instrumentos tecnológicos e a devida importância que eles exercerão na ação educativa permeada por educando e educadores. Pensando assim perceberemos que as tecnologias disponíveis, além de aliada nos proporcionarão novas formas de pensar, transformandonos nos novos educadores do mundo globalizado.

Daí o grande desafio para os educadores e do Brasil e do mundo, adaptar o conteúdo pedagógico e disciplinar aos novos instrumentos tecnológicos.

É consenso entre os especialistas que não basta apenas investir em laboratórios, salas multimídia e projetores de luz. Muitas escolas, mesmo aquelas que gastam rios de dinheiro em equipamentos de última geração, deixam de lado o treinamento dos professores. Sem mudança na metodologia, as novas ferramentas são subtilizadas (BRISO et al., 2009). 
A capacitação profissional e tecnológica dos educandos, dos educadores e da população em geral, desempenhará papel fundamental na promoção do crescimento econômico e no desenvolvimento socioeconômico dos países, com benefícios para cada indivíduo, sua família, as comunidades locais e a sociedade em geral.

Promover a capacitação tecnológica ou a educação tecnológica da população é, portanto, tarefa fundamental para qualquer sociedade contemporânea. No caso do Brasil em particular, pode ser um remédio eficiente contra a pobreza, as desigualdades e a exclusão social que caracterizam o país (QUEIROZ, 2007, p.32).

Nesse intuito as diversas esferas do governo vêm se empenhando nessa empreitada de levar as novas tecnologias às escolas

O surgimento de novas tecnologias, se por um lado tem estreitado os limites de tempo e distância de comunicação, por outro, tem aumentado a disparidade de oportunidades entre os que dominam o conteúdo de informática e as linguagens e os que não conseguem ler com competência. Nesse contexto, os brasileiros que não dominam os mecanismos de aquisição do conhecimento e têm, portanto, acesso limitado à tecnologia - os analfabetos e alfabetizados funcionais de nível rudimentar - encontram-se em situação de profunda desvantagem (QUEIROZ, 2007, p. 36).

Acredita-se que se trata de um processo em construção, fazer com que as tecnologias cheguem a todos os setores da sociedade, da educação e da produção econômica.

Verifica-se, portanto, que significativa parcela da população brasileira necessita de instrumentos de aquisição de conhecimento, geração de renda e de inserção social, mas não se encontra em idade de freqüentar a educação regular para capacitar-se. Para essas pessoas é preciso oferecer oportunidades de enfrentamento da exclusão e da falta de equidade social (QUEIROZ, 2007, p.36-37).

Muito além de modernizar a vida social está o desafio de se construir um processo de inclusão social e digital o que se tem verificando na implantação de milhares de telecentros comunitários em todas as regiões do país.

Políticas mais incisivas de educação continuada e de capacitação tecnológica da população brasileira podem ser eficazes instrumentos de inclusão e devem, portanto, integrar o projeto de desenvolvimento para o Brasil. Se o país pretende eliminar o gravíssimo problema da 
má distribuição de renda que o caracteriza como nação de desigualdades e de injustiça social, precisa investir, com urgência, na melhoria da qualidade da educação e na capacitação tecnológica dos brasileiros (QUEIROZ, 2007, p.37).

A industrialização efetivada a partir do século XVIII na Inglaterra fez da tecnologia seu ponto de partida fazendo com que

A produção de bens de consumo começou a possuir processos automatizados, os quais tornavam a mão de obra trabalhadora cada vez mais desnecessária e em contra partida, gerava um maior desempenho na produção. Neste período, surgiram alguns nomes que se destacaram, tanto no desenvolvimento da tecnologia, como no estudo do uso da mesma para obter uma melhor performance nos processos de produção das empresas. A partir daí, houve uma super especialização do trabalho assim como controle do mesmo por parte dos gestores. Toda essa mudança de contexto, dentro das organizações, levou ao aumento significativo de doenças que até então eram quase inexistentes (REIS, 2013).

Pensando na atualidade, sabemos que a tecnologia também tem contribuído na geração de emprego e renda e que alguns profissionais estão cada vez mais valorizados visto que as máquinas nem sempre executam todas as suas funções sem o ser homem. Sem falar que os trabalhos manuais também voltaram a ser valorizados, constituindo-se em requinte e diferencial na sociedade.

A tecnologia também tem promovido a cultura da necessidade de um atualizarse permanentemente.

Não é atoa que o jornal A folha de São Paulo publicou um artigo em que a informática na educação não era bem vista, alunos que tinham computadores em sala de aula tinham as mesmas notas dos que não tinham e a conclusão para isso era a orientação dada a eles. Por isso não basta ter o computador, têm que ter também a boa orientação.

No caso da escola, não deve o computador substituir o professor. A máquina deve isso sim, constituir-se num instrumento auxiliar, que dará ao professor mais tempo para a realização de outras tarefas que somente ele deve cultivar nos jovens. Desse modo, caberá cada vez mais à escola ensinar à criança e ao jovem o manejo desse equipamento. $\mathrm{O}$ mau uso do computador induz a indisciplina, as crianças não tem autocontrole suficiente para dominar-se, direcionado e restringindo o uso do computador. Além disso, a indução de indisciplina é exatamente o oposto de algo que a educação quer obter (THOMAZ, 2009). 
O governo brasileiro afirma que "PROUCA, tem como objetivo ser um projeto Educacional utilizando tecnologia, inclusão digital e adensamento da cadeia produtiva comercial no Brasil”. Assim,

O projeto OLPC foi apresentado ao governo brasileiro no Fórum Econômico Mundial em Davos - Suíça, em janeiro de 2005. Em junho daquele ano, Nicholas Negroponte, Seymour Papert e Mary Lou Jepsen vieram ao Brasil especialmente para conversar com o presidente e expor a idéia com detalhes. O presidente não só a aceitou, como instituiu um grupo interministerial para avaliá-la e apresentar um relatório. Após reuniões com especialistas brasileiros para debates sobre a utilização pedagógica intensiva das TIC (Tecnologias da Informação e Comunicação) nas escolas, foi formalizada uma parceria com a FacTI (Fundação de Apoio à Capacitação em Tecnologia da Informação) - FINEP (Financiadora de Estudos e Projetos) para a validação da solução da Organização OLPC, proposta originalmente pelo MIT (BRASIL, 2014).

Maria Osorio Marques (2006, p.104) afirma que “a tecnologia não é simplesmente ciência aplicada, mas ciência reedificada e impulsionada por instrumentos técnicos conceituais propositadamente instituídos." Nessa mesma linha de raciocínio, Adriana Spindola de Ataides (2014), diz:

A tecnologia é, sobretudo, desafio, inovações onde não podemos ignorá-la ou corrermos o risco de sermos devorados por ela. A partir do pressuposto de nos integrarmos à essa sociedade tecnológica, podemos destacar um dos maiores aparelhos capazes de expandir e atualizar os indivíduos nas mudanças culturais que a tecnologia vem dispondo, denominado "aparelho escolar", cujo princípio é a integração da sociedade ao seu meio social.

\section{A Experiência de Paraguaçu: resultados obtidos}

Ao tomarmos conhecimento da iniciativa inovadora desenvolvida pelo Centro de Educação Fazendo Acontecer "Ana Paula Silva Gomes" - CEFA, realizamos visitas in loco visando obter maiores informações sobre o projeto.

Após as primeiras visitas resolvemos elaborar um questionário contendo nove perguntas e as submetemos à diretora do Centro.

Para a primeira pergunta nosso intuito era saber como surgiu a ideia de utilizar a tecnologia para a obtenção do conhecimento e foi nos respondido que: 
A ideia surgiu da apresentação de um material didático feito para utilizar a tecnologia como ferramenta pedagógica apresentado por uma editora. $\mathrm{O}$ fato dos adolescentes utilizarem muito as novas tecnologias como forma de comunicação e entendimento nos fez voltar o olhar para como utilizá-las para formação e também como maneira de educá-los para utilizá-las com ética.

Na segunda pergunta queríamos saber qual foi a reação dos pais em relação ao uso da tecnologia em sala de aula e a diretora respondeu que:

Em um primeiro momento os pais foram muito resistentes, não conheciam essa tecnologia e tinham medos: dos alunos não usarem cadernos e assim não dominarem a escrita e ficarem muitos "viciados" no computador, a escola perdeu muitos alunos no começo do ano, pelo fato dos pais não apostarem nesta proposta.

Como projeto foi implementado em uma escola privada, logo, com fins lucrativos, perguntamos se o uso da tecnologia em sala de aula contribuiu para a matrícula de novos alunos a diretora responde que "no começo do ano a escola perdeu alunos, mas no decorrer, quando os resultados começaram a aparecer, os comentários do quanto as aulas são mais atrativas e dinâmicas a escola teve novas matriculas”.

Na quarta pergunta queríamos saber qual foi a reação dos educandos diante desta tecnologia, tendo sido respondido que:

Os alunos gostam muito de poder utilizar as tecnologias em aula, o
uso de jogos tornam-se aliados para os professores e desafio para a
turma, a oportunidade de debater vídeos do youtube, de interpretar
infográficos e tudo que o material permite dinamiza as aulas e amplia
o universo educativo. Esta realidade traz para a sala de aula uma
realidade que os jovens já vivenciam fora dela. Estes tornam-se mais
próximos dos professores que passam a falar "a língua deles".

Em seguida queríamos saber como os professores avaliam o ensino depois da implementação da tecnologia na didática e nos foi confirmado que "a avaliação é muito positiva, estes estão mais envolvidos, sentem-se desafiados e deslumbrados com um "mundo novo" e isto é contagiante".

Na sexta indagação tínhamos como objetivo saber quais os benefícios que o uso da tecnologia em sala de aula traria para a sociedade e obtivemos como resposta: "alunos melhor informados, mais críticos, tecnologicamente educados: sabem utilizar as novas mídias com ética. Cidadãos que sabem procurar informação e sabem como utilizá-las para melhorar a qualidade de vida destes e de seus pares". 
Para conhecemos melhor o público usuário perguntamos em que faixa etária é utilizada essas ferramentas tecnológicas, sendo conformado que "é utilizada com alunos do $6^{\circ}$ ano ao $9^{\circ}$ ano, do Ensino Fundamental dos 11 aos 14 anos".

Quando perguntamos o que a escola espera dos alunos que utilizam os meios tecnológicos em sala de aula foi nos explanado que "a escola espera formar cidadãos éticos e atuantes que saibam utilizar as tecnologias de forma positiva para que estas possam contribuir na formação destes e na atuação de cada um na sociedade da qual fazem parte".

Finalizando nossas indagações perguntamos quais os pontos positivos e negativos do uso da tecnologia em sala de aula, o que ficou muito claro na exposição seguinte:

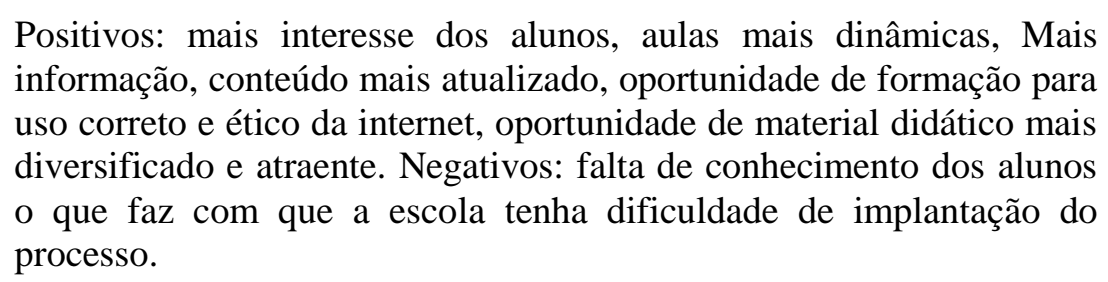

Podemos perceber que o desejo de inovar e adequar a vida escolar às novas tecnologias tem sido um grande desafio principalmente no ensino público ao passo que no ensino privado tem sido um grande diferencial.

\section{Considerações/conclusões}

A educação atualmente vem sendo modificada por grandes variações, novas tecnologias chegam a cada dia nas escolas, os alunos se interessam mais pelas aulas, os professores revigoram o conhecimento, transformando um ensino de qualidade e aprimorando suas técnicas e habilidades. Primeiramente, os pais se assustem pela bagagem de conhecimento que a escola dispõe aos alunos; não aceitando os novos métodos de ensino e aprendizagem, se preocupando com o abandono da escrita. É claro, a escrita é importantíssima para o aluno, não podemos deixá-la de lado, pois a mesma está presente todos os dias em nossas vidas e sem ela, não terá continuidade o ato de aprender e ensinar. Portanto, a sociedade revigora contra essa questão da tecnologia por invadir nossas redes de ensino, trazendo mais comodidade, facilidade e desempenho. Poucas escolas ainda aderiram essa técnica dentro da sala de aula, com medo dos alunos de perderem no tempo com os métodos, e não saberem aproveitar o uso da mesma, e 
serem prejudicados. Outras já desenvolvem para que os alunos tenham em primeira mão um ensino diferenciado, mas sempre aconselhando os usos em sala de aula. Meras são as escolas que acreditam em ensino de qualidade; nem sempre a tecnologia pode ser deixada de lado, quando o assunto é escola, ato de aprender, pensar e ler. A tecnologia é consequência do ensino, e o ensino é demonstrado como forma aderente da sociedade, da qual constitui nosso cotidiano, sendo visada diariamente. As pessoas pensam e rotula que nem tudo que é bonito tem valor, nem tudo que é novidade vem do ensino de um educador. Educar é muito mais que uma profissão, é um ato de transformar pequenos homens, em cidadãos ativos!

As tecnologias educacionais como o computador e a internet são ferramentas indispensáveis em nossas vidas, pois auxilia na aprendizagem e na formação dos docentes e discentes. Tais meios tecnológicos estão sendo utilizados com eficiência e de forma adequada gera aprendizado e um aumento da criatividade e motivação dos alunos, ou seja, a aula se torna atrativa e interativa. Também é importante, pois seu uso contribuirá contra a pobreza, as desigualdades e a exclusão social que caracterizam o país.

Conclui-se que o uso das tecnologias dentro da sala de aula veio a melhorar o ensino da educação básica ampliando o acesso de ensino em escolas.

Esta com os seus meios mais modernos podem nos proporcionar uma educação mais adequada para os meios de vida do mundo de hoje.

Visando por meios de educação se torna indispensável o processo da tecnologia em nossa pratica pedagógica, estando o professor contribuindo para a formação de novos indivíduos.

\section{THE TECHNOLOGY REVOLUTIONIZING THE TEACHING AND LEARNING PROCESS? THE EXPERIENCE PARAGUAÇU IN THE STATE OF MINAS GERAIS.}

ABSTRACT: We can't deny that technological advances are each day closer to the people and has gradually taken the school environments with a discursive formulation that promote greater integration of students and improving the method of teaching and learning , as it signals to be occurring at the Center Education Making it Happen "Ana Paula Silva Gomes," private school council miner Paraguaçu. Is that even what has happened? We know that improper use of this tool can block the development of creativity and the ability to synthesize the information received. Most often a lack of discernment, their own children and youth are the most affected by this seductive technology, as parents, because of the very logic of the world do not enjoy the work conditions to oversee studies that take place before computers and the internet. 
Moreover, the classroom itself can occur detachment and coldness in the relationship between educators and students. So that parents, teachers and education professionals need to monitor very carefully deploying these innovative technologies in classrooms that do not jeopardize the whole process of teaching and learning in the future have an army of people who will not know to write, read and count.

KEYWORDS: Education. Technology. Initiative. Learning. Contradiction.

\section{REFERÊNCIAS}

ATAIDES, A. S. Tecnologia, educação e autonomia. Disponível em:

$<$ http://meuartigo.brasilescola.com/pedagogia/tecnologia-educacao-autonomia.htm>. Acesso em: 27 mai. 2014.

BACELAR, D. Os Chats: uma ferramenta didáctica. 2010. Disponível em: <http://superdom.blogs.sapo.pt>. Acesso em: 27 mai. 2014.

BRASIL. Ministério da Educação. O Projeto: conheça o UCA. Disponível em: <http://www.uca.gov.br/institucional/projeto.jsp>. Acesso em: 27 mai. 2014.

BRISO, C. B. et al. Escola do futuro: o papel do professor: guiar o aprendizado. 2009. Disponível em: <http://veja.abril.com.br/noticia/educacao/papel-professor-manter-seantenado>. Acesso em: 27 mai. 2014.

DALAPOSSA, K. C. Tecnologia na Educação. Disponível em:

<http://meuartigo.brasilescola.com/educacao/tecnologia-na-educacao.htm>. Acesso em: 27 mai. 2014.

EDUCANDO.COM. Vantagens e desvantagens da tecnologia na educação. 2011. Disponível em: <http://educandocomffp.blogspot.com.br/2011/10/vantagens-edesvantagens-da-tecnologia.html>. Acesso em: 27 mai. 2014.

MARQUES, M. O. A escola no computador: linguagem rearticulada, educação outra. Ijuí: Unijuí, 2006.

QUEIROZ, Ângelo Azevedo... [et al.] Organizadores. Capacitação tecnológica da população / relator: Ariosto Holanda; Brasília: Câmara dos Deputados, Coordenação de Publicações, 2007. 309 p. - (Série cadernos de altos estudos; n. 4)

REIS, J. Tecnologia, aspectos positivos. 2013. Disponível em: <http://internetesociedade.blogspot.com.br/2013/02/tecnologia-aspectos-positivose.html>. Acesso em: 27 mai. 2014.

THOMAZ, J. R. Pontos negativos do uso tecnológico. 2009. Disponível em: <http://jaimerobertothomaz.blogspot.com.br>. Acesso em: 27 mai. 2014. 